\title{
A Study on School Architecture and Spatial Planning Measures in Response to Changes Caused by COVID-19 Pandemic
}

\author{
Jinju Jung ${ }^{1}$ \\ ${ }^{1}$ Professor, Department of Architecture, Cheongju University, Korea, jinjuj@cju.ac.kr
}

\begin{abstract}
Due to structural social changes such as the severely declining birth rate, a decrease in the school-age population due to aging, and the unprecedented global COVID-19 pandemic, existing school facilities and spaces are in need of fundamental changes from the conventional method of using basic classrooms and support facilities to a more flexible application method that can cope with new situational conditions. The purpose of this study is to provide basic data that can be applied to the school site in the future by considering the decrease in the number of students and school architecture and space plans to cope with changes brought by COVID-19 pandemic. The research method was approached and studied from an architectural planning aspect slightly different from the general research method in the fields of humanities and sociology, which analyzes actual school design cases. To study and analyze school-age population decline trends the following data were collected such as the resident registration population data, Statistics Korea's special projection data for the country's future population, the data of the Teacher Policy Division of the Ministry of Education that applies the enrollment rate, and KEDI. Also, drawings and field conditions are investigated and analyzed for actual cases of Korea and Japan from 2018 to 2019. The conclusion of the study is as follows. It is deemed possible to respond by fully utilizing the school space with a plan that combines face-to-face class and class mirroring or a plan that combines face-to-face class and home mirroring. Some of the flexible responses for new schools or school spaces that can be expanded or remodeled are to convert the corridors into a multifunctional 7.5 $\mathrm{m}$ space, which combines the function of a $4.5 \mathrm{~m}$ wide workspace with the function of an ordinary $3 \mathrm{~m}$ passage, and to implement changes by means of zoning by grade level and improving student mobility guides designed to minimize student mobility and contact. And it is necessary to change planing a school that maximizes flexibility and variability.
\end{abstract}

Keywords: School Architecture, COVID-19, Decrease in the Student Population, Flexible Responses for New Schools

\section{Introduction}

Since 2020, the world has been grappling with unprecedented challenges due to COVID-19, and the lives and behaviors of individuals and societies are rapidly changing. In Korea, the government is implementing various quarantine guidelines to reduce the spread of infections. Depending on the severity of pandemic measures, students may not go to school or social distancing guidelines must be strictly observed at schools even when limited attendance is allowed.

Since this phenomenon requires a fundamental change from the conventional method of using basic classrooms and supporting facilities to shift to a flexible method that enables responses to completely

Received: September 1, 2021; $1^{\text {st }}$ Review Result: October 17, 2021; $2^{\text {nd }}$ Review Result: December 2, 2021 Accepted: January 29, 2022 
new situations with regard to existing school facilities and spaces, there is a demand for relevant research to address these needs in multifaceted directions.

Meanwhile, it is widely known that in South Korea, the decrease in the school-age population is proceeding at a very rapid pace in tandem with an aging population due to changes in the social structure such as a severely low birth rate. According to the statistics of the Ministry of Education's Teacher Policy Division (2020), the school-age population is expected to decrease from 4.49 million in 2020 to 3.32 million in 2030, a decrease of 1.17 million, or $26 \%$. This decline of $26 \%$ in the school-age population makes it possible to project that one-fourth of schools will disappear or that one-quarter of the school space will become unused[1]. Furthermore, such preparation requires major changes in education policies and overall education finance.

Of course, COVID-19 and the decrease in the number of students are not directly related to each other. However, it can be fully expected that these two phenomena will promote major changes in school space in the future. Given these conditions, it will be necessary to prepare for various factors of change in the future educational environment that may affect school architecture and space like the space of students who respond to the COVID-19 educational environment. Of Course, such preparation requires major changes in education policies and overall education finance. Specifically, it entails changes in the curriculum, changes in teaching and learning methods, a reduction of the number of students per class, changes in faculty acquisition policies, changes in school architecture and space, and increases in the education budget. Also, it is true that studies related to school spaces corresponding to pandemics such as COVID-19 have not been conducted in various ways so far.

In this context, this study aims to provide basic data for building plans that can be practically applied to school sites in the future by examining school architecture and space plans that can cope with the decrease in the number of students and COVID-19.

\section{Research Methodology}

\subsection{Target and Analysis Method of Statistics and Case Study}

This study was conducted with the following contents and methods. The research method was approached and studied from an architectural planning and design aspect slightly different from the general research method in the fields of humanities and sociology, which analyzes actual school design cases. First, the trend and prospects of the decrease in the number of students are predicted and analyzed through educational statistics information from the Ministry of Education, Statistics Korea's special projection data and KEDI. Second, as a way to respond to various factors of change in the future educational environment, drawings and field conditions are investigated and analyzed for actual cases of Korea and Japan that visited from 2018 to 2019. Third, through this field survey, applicable methods of complexation schools, integrated operating schools, general media centers, and future interactive classrooms are proposed. Fourth, it proposes an example(draft) of architectural planning for a space that responds to the COVID-19 pandemic variables. Fifth, this study suggests a multifaceted approach to improving the curriculum and system in the future and recommends related studies in architectural planning for the transition to flexible and variable school architecture and space.

\subsection{Data and Analysis of School-Age Population Decline Trends}

To study and analyze school-age population decline trends the following data were collected such as the resident registration population data(as of the end of 2018), Statistics Korea's special projection data for the country's future population(as of March 2019), and the data of the Teacher Policy Division of the Ministry of Education that applies the enrollment rate, and KEDI. 
According to the statistical data above, for the past 5 years to project future figures, the number of elementary school students will diminish by $930,000(35 \%)$ and middle and high school students by $250,000(13.2 \%)$, with a total decline of 1.17 million(26\%), compared to 2020[1].

Such a decrease in the number of students is likely to lead to a decrease in the number of students per class. The number of students per elementary school class in South Korea is 23, which is 2 more than the OECD average of 21 . The average number of students per Korean class in secondary school is 27.6, which is about 3 more than the OECD average of 23. According to statistics on the change in the number of students per class from 2005 to 2017, the number of students decreased by 5.1 from 32.6 in 2005 to 27.5 in 2010, which is a very significant decrease compared to the OECD average. From 2005 to 2010, the number decreased at an average rate of 1.02 per year, from 2010 to 2013 at an average rate of 1.16 per year, and from 2014 to 2017 , at an average rate of 0.225 per year, thus registering a falling reduction rate. However, based on the trend of a decline over the past five years, it can be predicted that it will take 4.5 years to lose one student per elementary school class in South Korea[1].

[Table 1] 2020 2035 Estimation of School-age Population Decrease[1]

\begin{tabular}{|c|c|c|c|r|r|r|r|r|r|r|r|r|r|r|r|r|}
\hline Classification & $\mathbf{2 0 2 0}$ & $\mathbf{2 0 2 1}$ & $\mathbf{2 0 2 2}$ & $\mathbf{2 0 2 3}$ & $\mathbf{2 0 2 4}$ & $\mathbf{2 0 2 5}$ & $\mathbf{2 0 2 6}$ & $\mathbf{2 0 2 7}$ & $\mathbf{2 0 2 8}$ & $\mathbf{2 0 2 9}$ & $\mathbf{2 0 3 0}$ & $\mathbf{2 0 3 1}$ & $\mathbf{2 0 3 2}$ & $\mathbf{2 0 3 3}$ & $\mathbf{2 0 3 4}$ & $\mathbf{2 0 3 5}$ \\
\hline Kindergarten & 1,250 & 1,151 & 1,045 & 968 & 914 & 879 & 872 & 891 & 925 & 959 & 993 & 1,024 & 1,049 & 1,062 & 1,064 & 1,058 \\
\hline $\begin{array}{c}\text { Elementary } \\
\text { School }\end{array}$ & 2,717 & 2,710 & 2,696 & 2,600 & 2,474 & 2,334 & 2,206 & 2,055 & 1,915 & 1,831 & 1,797 & 1,796 & 1,823 & 1,876 & 1,940 & 1,999 \\
\hline $\begin{array}{c}\text { Junior High } \\
\text { School }\end{array}$ & 1,358 & 1,373 & 1,361 & 1,358 & 1,379 & 1,398 & 1,354 & 1,325 & 1,292 & 1,240 & 1,143 & 1,037 & 961 & 908 & 874 & 866 \\
\hline High School & 1,382 & 1,337 & 1,315 & 1,354 & 1,369 & 1,357 & 1,354 & 1,375 & 1,394 & 1,350 & 1,321 & 1,287 & 1,236 & 1,139 & 1,034 & 958 \\
\hline Total & 6,707 & 6,571 & 6,417 & 6,280 & 6,136 & 5,969 & 5,786 & 5,647 & 5,526 & 5,380 & 5,254 & 5,146 & 5,069 & 4,985 & 4,912 & 4,881 \\
\hline
\end{tabular}

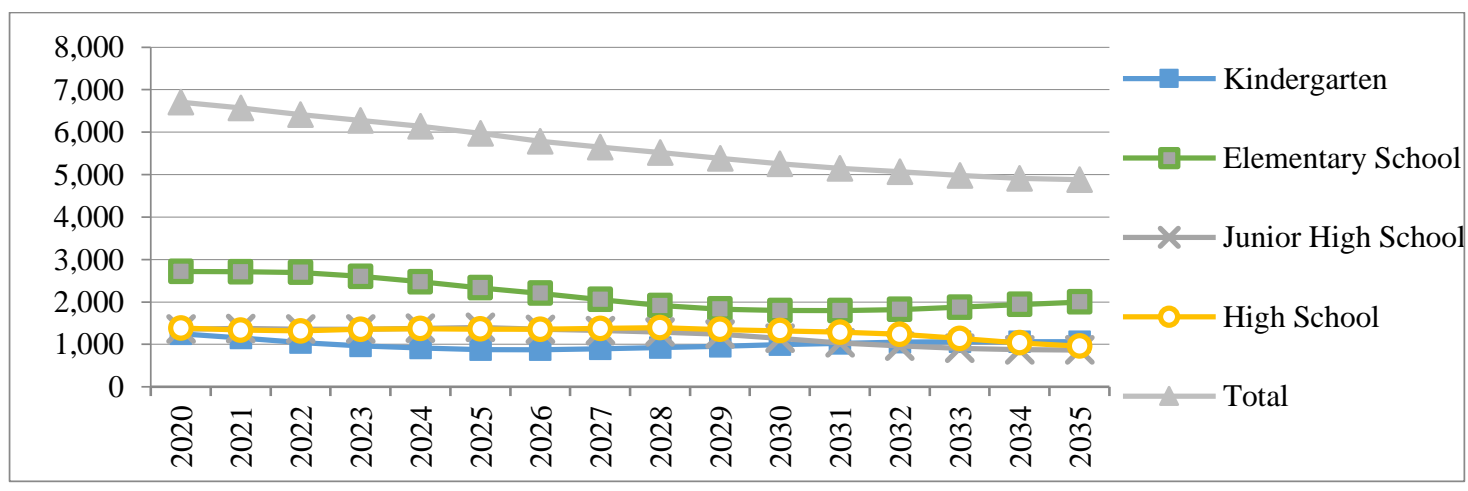

[Fig. 1] 2020 2035 Estimation of School-age Population Decrease[1]

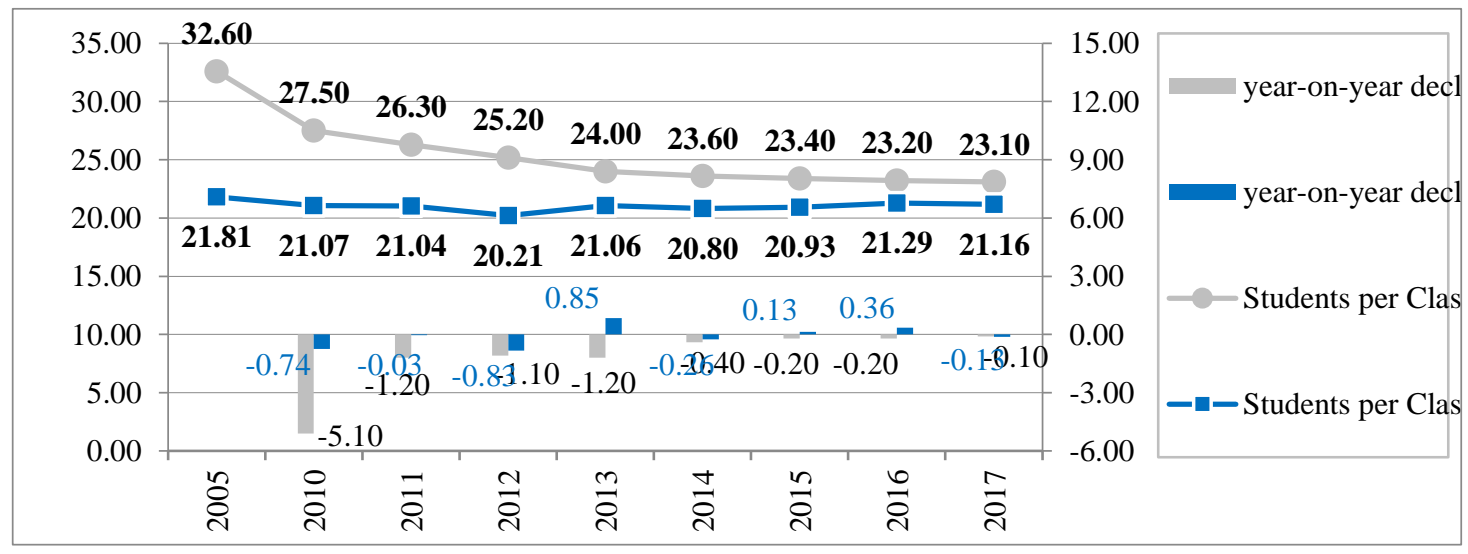

[Fig. 2] Changes in the Number of Students per Class of Elementary Education in Korea Between 2005 2017[2] 
These statistics can be fully utilized for education finance, teacher recruitment, or the construction of school facilities. However, the policy of maintaining an appropriate level in the number of students per class through a reduction in the number of students causes a financial burden on the government in various aspects, such as an increase in the total construction cost, an increase in the cost of securing school land due to an increase in the number of schools, securing additional teachers, and redevelopment of the curriculum.

\section{Results and Discussion}

The research method was approached and studied from an architectural planning aspect slightly different from the general research method in the fields of humanities and sociology, which analyzes actual school design cases. As a way to respond to various factors of change in the future educational environment, drawings and field conditions are investigated and analyzed for actual cases of Korea and Japan that visited from 2018 to 2019.

\subsection{School Space that Responds to Changes in the Educational Environment}

\subsubsection{Composite Schools Combining Local Community Facilities}

The principle of restricting the establishment of new schools due to a decrease in the number of students or requiring schools to be of an appropriate minimum size to avoid undersized schools inevitably reduces the opportunities for creating schools. However, as the demand for new schools continues to rise due to the development of new towns and the redevelopment of the old downtown areas, the establishment of a school through complex integration with local public facilities rather than the establishment of an independent school emerges as an alternative.

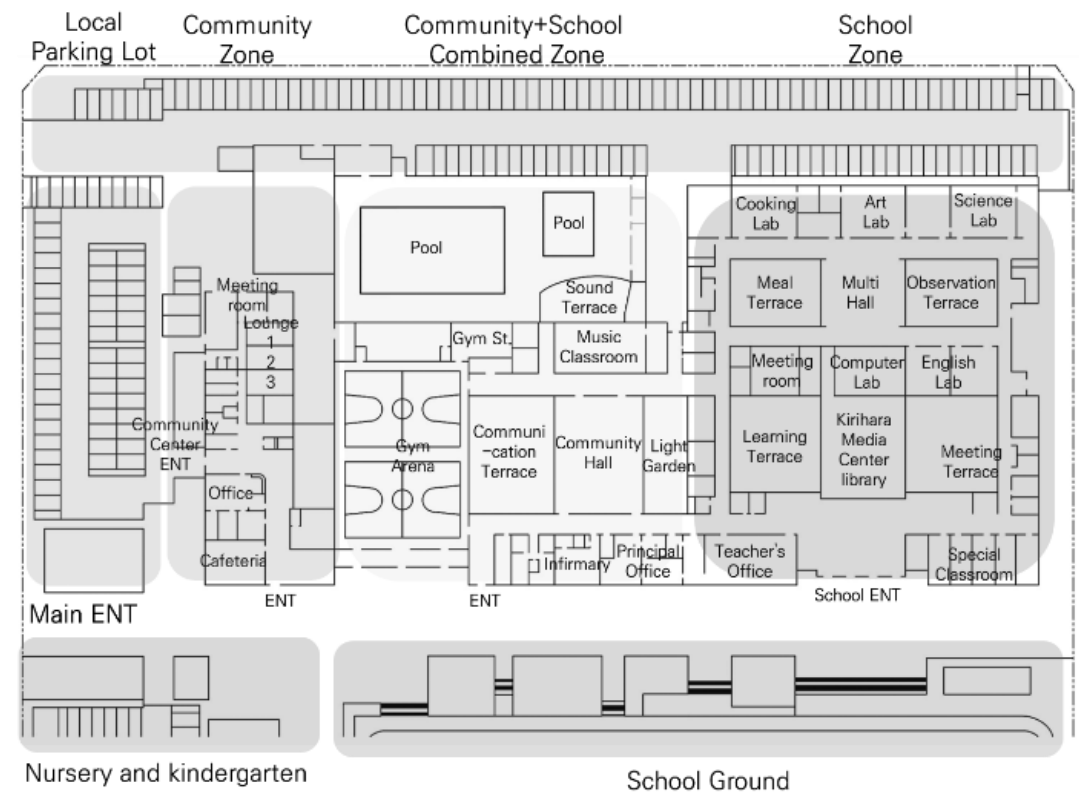

[Fig. 3] Kirihara Community/Elementary School, Omihachiman, Shiga, Japan[3]

In South Korea, school facilities have been mainly combined with local public facilities such as libraries, parking lots, and sports facilities since the early first decade of the new millennium. Since 2015, the Dongtan area of Hwaseong, Gyeonggi-do has implemented such integration, which combines public libraries, the Information and Communication Technology(ICT) education facilities, youth media 
facilities, performing arts facilities, lifelong education facilities, and music and art cultural centers with planned elementary and middle schools, stage by stage. By comparison, Japan is quite advanced in such developments, and many cases of school facility integration have been carried out in Japan. Kirihara Elementary School, located in a dense farmland and residential area near Omihachiman Station in Omihachiman City, Shiga Prefecture, Japan, is a composite school that combines local community facilities and an elementary school. The kindergarten(childcare facilities), regional community hall, regional disaster prevention base center, gymnasium, swimming pool, and library were built on a large scale in 2016 by implementing integration with the elementary school, which has served as a representative example of a composite school in Japan.

\subsubsection{Schools Integrating Elementary-Middle and Middle-High Levels}

A decrease in the number of students leads to a decrease in the number of new schools, and on the other hand, naturally results in the establishment of small schools. But, since it is required that newly established schools should be of an appropriate size, a natural consequence has been the emergence of elementary/middle schools or middle/high schools. The establishment of such integrated schools has been increasing in South Korea and Japan.

[Table 2] Comparison of School System by OECD Countries[4]

\begin{tabular}{|c|c|c|c|c|c|c|c|c|c|}
\hline \multirow{3}{*}{ Classification } & \multicolumn{4}{|c|}{ School System } & \multirow{3}{*}{ Classification } & \multicolumn{4}{|c|}{ School System } \\
\hline & \multicolumn{2}{|c|}{ Primary Education } & \multicolumn{2}{|c|}{$\begin{array}{c}\text { Elementary-Junior High- } \\
\text { High } \\
\end{array}$} & & \multicolumn{2}{|c|}{ Primary Education } & \multicolumn{2}{|c|}{$\begin{array}{c}\text { Elementary-Junior High- } \\
\text { High } \\
\end{array}$} \\
\hline & $2 \mathrm{Yrs}$ & Others & $6-3-3$ & Others & & $2 \mathrm{Yrs}$ & Others & $6-3-3$ & Others \\
\hline Austria & 2 & & & $4-9$ & Italy & & 3 & & $5-3-5$ \\
\hline Australia & 2 & & $6-3-3$ & & Japan & 2 & & $6-3-3$ & \\
\hline Belgium & & 3 & & $6-6$ & Korea & 2 & & $6-3-3$ & \\
\hline Chile & $\mathrm{N} / \mathrm{A}$ & & N/A & & Latvia & 2 & & & $9-3$ \\
\hline Colombia & & 3 & & $6-4-2$ & Lithuania & & 3 & & $4-5-3$ \\
\hline Czech & 2 & & & $9-2$ (or 4) & Luxembourg & $\mathrm{N} / \mathrm{A}$ & & $\mathrm{N} / \mathrm{A}$ & \\
\hline Denmark & & 3 & & $9-3$ & Mexico & 2 & & $6-3-3$ & \\
\hline Estonia & & 4 & $6-3-3$ & & Netherlands & & 3 & & $7-2-4($ or 5 or 6$)$ \\
\hline Finland & 1 & & $6-3-3$ & & New Zealand & 2 & & & $6-2-5$ \\
\hline France & & 3 & & $5-4-3$ (or 2) & Norway & 2 & & & $7-3-3$ \\
\hline Germany & & 3 & & $4-5-4$ & Poland & 2 & & & 6-3-3(or 4) \\
\hline Greece & 2 & & $6-3-3$ & & Portugal & & 3 & & $4-2-3-3$ \\
\hline Hungary & 2 & & & $8-4$ & Slovak & $\mathrm{N} / \mathrm{A}$ & & $\mathrm{N} / \mathrm{A}$ & \\
\hline Iceland & 2 & & & $6-3-2-1$ & Slovenia & $\mathrm{N} / \mathrm{A}$ & & $\mathrm{N} / \mathrm{A}$ & \\
\hline Turkey & 2 & & & $5-4-4$ & Spain & & 3 & & $6-4-2$ \\
\hline $\begin{array}{l}\text { United } \\
\text { Kingdom }\end{array}$ & 2 & & & $4-5-2$ & Sweden & & 5 & & $3-3-3-3-$ \\
\hline United States & & 1 & & $5-3-4$ & Switzerland & 2 & & & $6-3-4$ \\
\hline Ireland & & 1 & & $8-5(\sim 6)$ & Canada & 2 & & & $6-2-4$ \\
\hline Israel & & 1 & $6-3-3$ & & & & & & \\
\hline
\end{tabular}

In South Korea, the 6-3-3 school year system currently in effect in 2021 has not changed for about 70 years. The 6th graders of elementary school 70 years ago and the 6th graders of elementary school today are clearly different in their way of thinking, values, and physical maturity. However, comparing the education system by OECD countries, only 8 of its 37 member countries maintain the 6-3-3 school system, accounting for only $21 \%$. Nearly $79 \%$ of countries around the world are already implementing various changes in school systems such as system change, system integration, credit system, and no- 
grade system, or are attempting other changes in the systems. A key characteristic of these $79 \%$ of countries is that they mostly link primary and secondary education. Their high schools are open to the possible routes of advancing to college and choosing a career, and they are implementing a system that enables students to freely choose. This trend has great implications for South Korea, which is preparing for a new academic system reorganization.

On the 3rd floor of Toegye Elementary \& Middle School in Chuncheon, which opened in March 2021, the library, rest area, and practice room are zoned at the center of the third floor as an area shared by elementary and middle school students, with the area for the 1st year of middle school placed in the upper right corner and the area for the 3rd and 4th grades of elementary school available in the lower center. The integrated elementary-middle school does not have two separate buildings but has an elementary school and a middle school area in the same space on the same floor of a building. In an integrated school, interdisciplinary convergence and exchange of elementary and middle school courses occur naturally. Exchanges between students and teachers also occur. When organizing and planning spaces, to promote convergence and exchange, the spaces that can be shared between the two school levels should be fully shared, and the spaces freed up by sharing must be returned to elementary and middle school students as a space dedicated to their needs. At present, it is common for elementary and middle schools to be in operation adjacent to each other without a fence, with separate dedicated spaces for each. This case will also have great implications for planning integrated schools in the future.

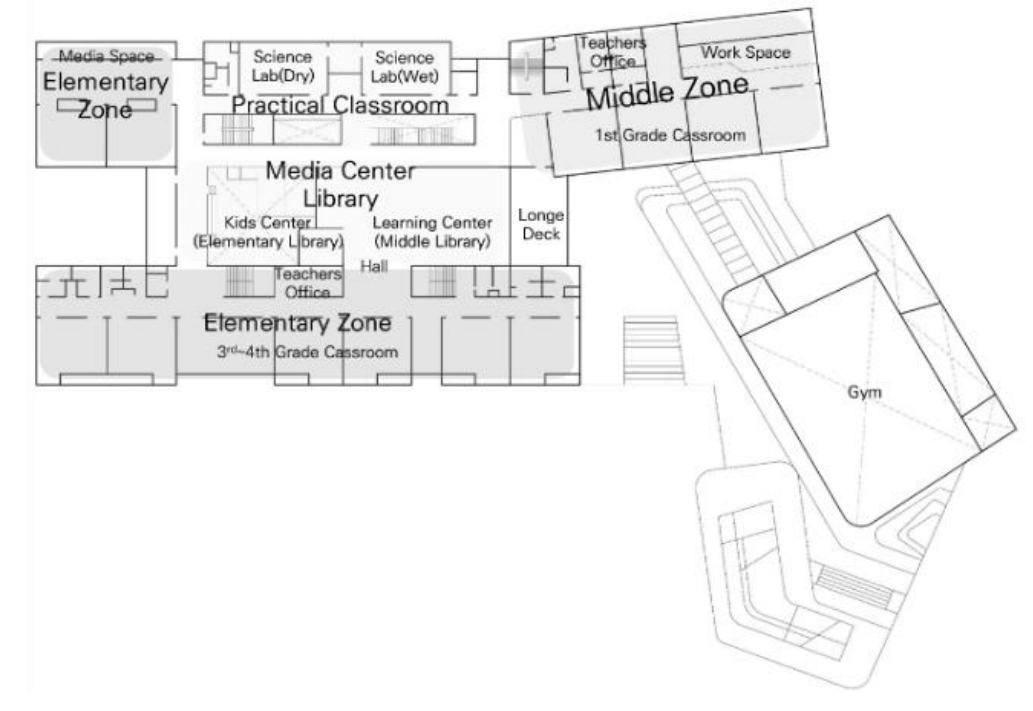

[Fig. 4] Chuncheon Toegye Elementary and Middle Integrated School(2021)[5]

\subsubsection{Comprehensive Media Centers Combined with Library and Interactive Classrooms}

The decrease in the number of students is also strongly related to the emergence of comprehensive media centers. It is often said that reading is the foundation of cultivating creativity. However, creativity is not taught in class. Many have argued that reading can directly and indirectly help foster creativity. Therefore, recently there has been growing emphasis on the importance of spaces related to a library in schools. In the past, people obtained most information from books, but now often acquire information through computer labs and the internet. As the acquisition of information is made possible through access to the internet or through books, the library and the computer room are interlinked. Since the library is a convergence space where exchanges among students, between students and teachers, and between classes and subjects take place, school libraries have been evolving away from the past practice of serving merely as a library, and the stereotypical approaches of the past must be changed. Now is the time to explore efforts to transform this space made possible by the decrease in the number of students 
into a comprehensive media center space that functions as a composite space for creative convergence[6].

One example is the general media center of Gifu Elementary School in Gifu, Japan. The media center is located in the center of the space, and the library is located on the north side. Since the entire first floor is not blocked by walls, a reading space, a space for presentation classes, a makeup education space, various practical classrooms. are provided through comprehensive zoning. This site is being used as a space for a comprehensive media center where convergence classes linking the same subjects and classes linked with other subjects can be conducted, and classes can be combined with each other. When it comes to changes in the Information and Communication Technology(ICT) learning environment, many have proposed future-oriented schools and classrooms. It is unnecessary to make all futuristic classrooms into computer rooms. As for the wireless internet environment and the configuration of classrooms with high-end equipment and facilities, such amenities will be useful for some classrooms, but they are not required in all classrooms. Then, it is needed should the space be organized to become an optimal classroom that meets future needs.

It is essential to have a space and environment where students and teachers, student peers, and even classes and external parties can interact with each other within the classroom. The word interactive implies that the sender and receiver can exchange contents. Therefore, simply having a computer room environment is not an ideal future classroom. Research should be approached with a vision of a future interactive classroom where contents are created in the classroom by someone, be it a teacher or a student, and the contents can be freely and interactively used in real-time with people in the classroom and with people outside the classroom or outside the school.

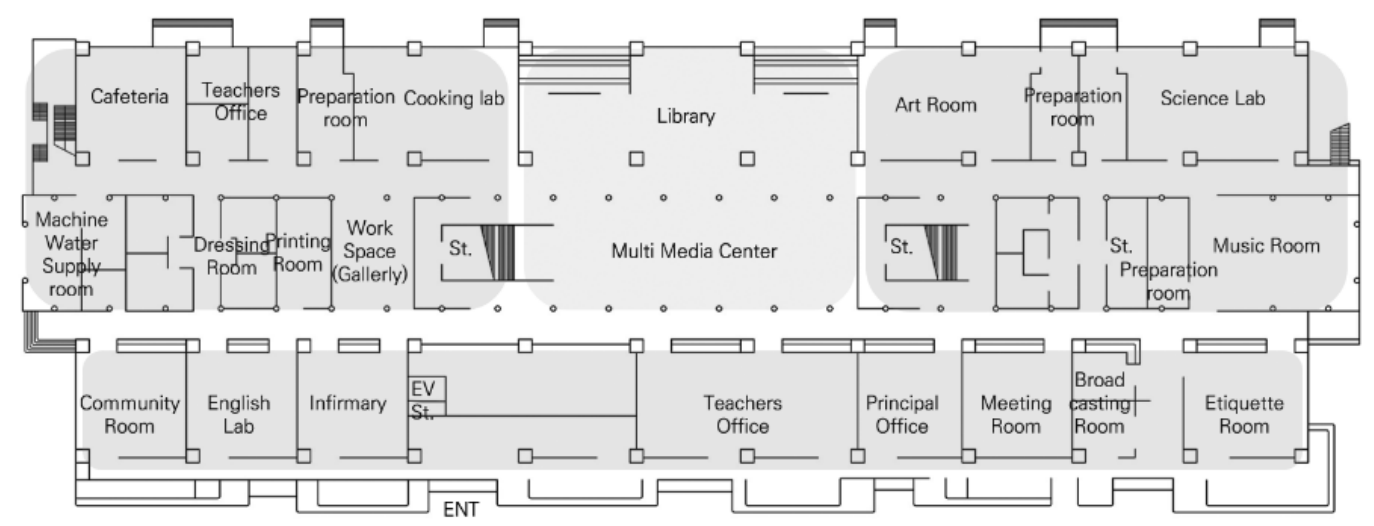

[Fig. 5] General Media Center, Gihoo Elementary School, Gihoo, Japan

\subsection{School Space Utilization Plans in Response to COVID-19}

This part was conducted for two plans. One is a plan to utilize the existing classroom environment that now examines plans to use the classroom environment as it currently exists in schools. The other is responses for new schools or spaces that can be expanded or remodeled. Recently, the Ministry of Education and some regional education offices are pushing for two-thirds of students to go to school and all students(divided by morning/afternoon). However, it is considerd the plan assuming that a third of the students go to school. This is because it is the most appropriate number of students to keep the $2 \mathrm{~m}$ distance between students, assuming that COVID-19 could worsen or another pandemic caused by another totally unpredictable infection.

\subsubsection{Plans to Utilize the Existing Classroom Environment}

The study now examines plans to use the classroom environment as it currently exists in schools. 


\section{1) Conditions in which Only $1 / 3$ or $2 / 3$ of Students Physically Attend School}

First of all, current school attendance by students needs to be tracked. In elementary and middle schools, 1/3 (2/3 depending on the situation) of the entire student body attends school. To be more precise, elementary schools admit two grades, and secondary schools admit only one grade onto the school premises, so only $1 / 3$ of their entire student body may be present in school classrooms. Only $1 / 3$ of the students physically attend school, but when they enter a school classroom, $100 \%$ of the same students find themselves in the classroom as previously. It is because they only go into their designated classroom. While only $1 / 3$ of the entire student body attends school, a single classroom remains holding students at $100 \%$ capacity, as $2 / 3$ of the classrooms remain empty and unused. Then, assuming that $1 / 3$ of the students attend school, it is necessary to consider whether it is advisable to leave $2 / 3$ of the classroom space unused or how to use these classrooms more efficiently.

\section{2) Simultaneous Implementation of Face-to-Face Classes and Classroom Mirroring Classes}

Place $1 / 3$ of the students in one central classroom and the remaining $2 / 3$ of the students in the adjacent classrooms. In the $1 / 3$ of the central classroom, the teacher conducts class face-to-face, and in the other $1 / 3$ and remaining $1 / 3$, teaching assistants provide support or observe, so that what the teacher is performing is mirrored in both classrooms. Assistant teachers are placed in the mirrored classrooms on both sides, and screens are installed on which the teacher's class contents are displayed. In addition, if a screen is installed on the back wall of the classroom of the teacher who is conducting the face-to-face class so that the faces of the students taking the mirroring class may be seen, the class can proceed very naturally. Students can take classes while fully utilizing the facilities in the school.

\section{3) Simultaneous Implementation of Face-to-Face Classes and Mirrored Classes at Home}

Another method assumes that only $2 / 3$ of the space is used when it is difficult to use $100 \%$ of the school facilities. Again, 1/3 of the students attend school, the teacher conducts class face-to-face in one classroom, and $1 / 3$ of the students study through mirroring in the next classroom. The remaining $1 / 3$ of students who are unable to attend school take online mirrored class at home. Instead of merely watching EBS classes, they watch the contents of the teacher's face-to-face class. This class mode is sufficiently possible by means of handling the mirrored class in the ICT environment in the existing classroom conditions.

\subsubsection{Variable Responses for New Schools or School Spaces that Can be Expanded or Remodeled}

The study considers an alternative concept for new schools or existing schools that can be expanded or remodeled in the direction of the corridor.

\section{1) Converting Corridors into Workspaces}

This plan assumes that 33 students are taught in one classroom as currently practiced. With social distancing under the current COVID-19 conditions, if more students want to receive lessons in one classroom, the classroom area needs to be expanded to create additional space. Currently, the back wall of a classroom is the site for the front blackboard of the back classroom, so it cannot be removed or replaced[7]. Also, if the situation normalizes later, it will cost money to restore the walls or schools will simply run out of space. Therefore, it would be more efficient to obtain more space through extension to the side of the hallway rather than towards the back of the classroom. This takes the concept of a corridor beyond the concept of a simple passage to the concept of a composite 'workspace' with functions such as exchange, rest, preparation, and home base. For this purpose, a space of $7.5 \mathrm{~m}$ can be reconfigured to combine the function of a $4.5 \mathrm{~m}$ wide workspace with the function of an ordinary $3 \mathrm{~m}$ passage. 




[Fig. 6] Transforming a Corridor from an Existing Passage Concept into a Workspace Concept and Classes in an Extended Place to the Workspace
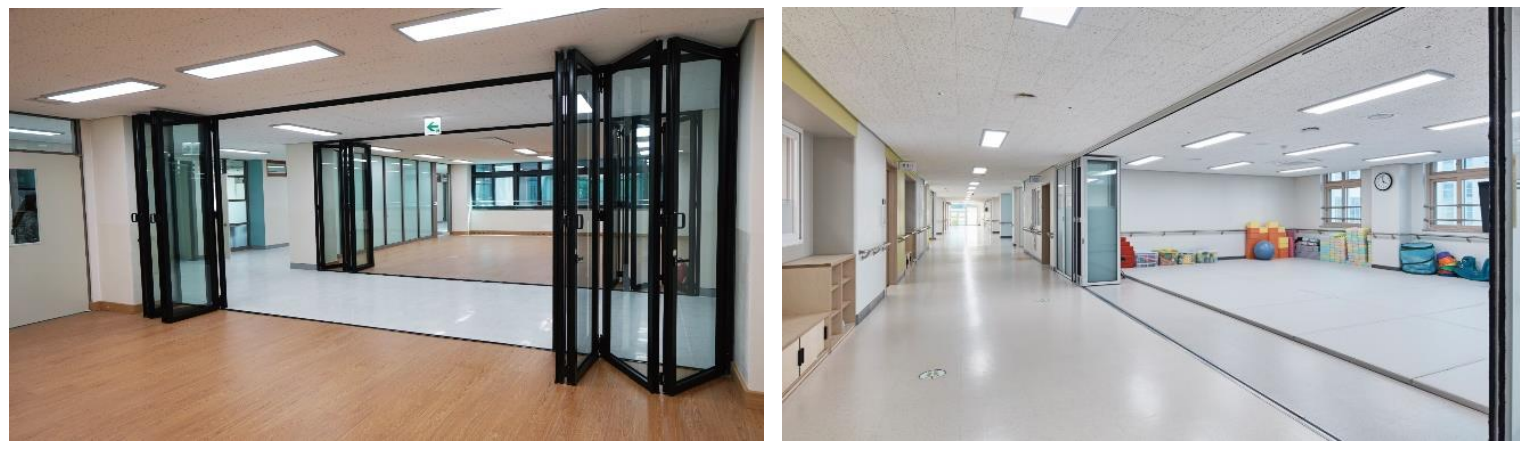

[Fig. 7] Cases of Expansion Classroom of Sejong High School and Daegu Yeahram School(@D\&B Architecture Design Group)

In the event of COVID-19 or a similar situation, the classroom space will be expanded toward the workspace to ensure a sufficient distance of $2 \mathrm{~m}$ between students and a classroom environment that allows $50 \%$ of students to take class. If the mirroring class mode is also used, the teacher can conduct a face-to-face class in the expanded classroom, and a mirrored class with an assistant teacher in another classroom can be conducted. There are several schools that already have this type of classroom. In the case of Sejong High School and Daegu Yeahram School, a multi-purpose space between the classrooms is opened with a folding door, so it is possible to expand and utilize the two spaces or to return to the normal arrangement.

\section{2) Conversion through Zoning by Grade Level and an Improvement of Student Mobility Guides}

This is a flat layout concept that includes the conversion of the zoning for each grade level and guidelines for the movement of students in new schools.

In the COVID-19 situation, social distancing is one of the key preventive measures, and it is important to minimize mobility and contact among students in the school. Even if $1 / 3$ of students attend school, normal mobility and contact within the school are not as easy as before. For the plan of a new school that addresses these conditions, various forms can be proposed according to the intention of a designer. The following proposes a concept with the conversion through zoning by grade level and an improvement of student mobility guides.

For example, zoning establishes clusters of 3 or 4 classes in each, and an independent public facility (stairs room, toilet, and washbasin) is arranged in each cluster. The plan is to minimize vertical and horizontal mobility and contact by allowing two classes to use the independent public facility normally used by three or four classes during COVID-19. Horizontal mobility between classes within a cluster is possible, and the movement to the upper and lower floors or adjacent buildings such as administrative areas, practice classrooms, restaurants, and auditoriums should be approached only through an independent vertical line of mobility within the cluster to minimize contact with each other. 


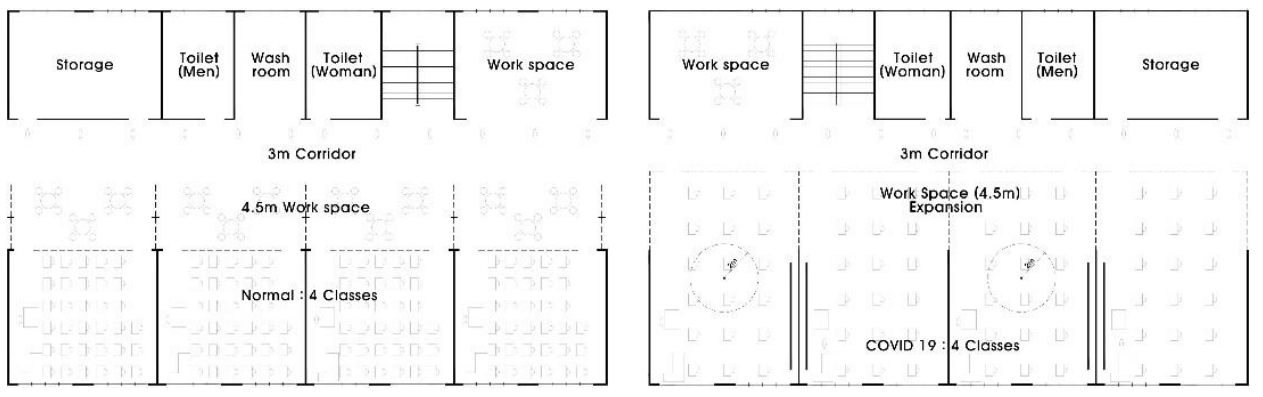

[Fig. 8] Cluster Zoning Concept based on 3 4 Classes, with Independent Public Facilities per Cluster

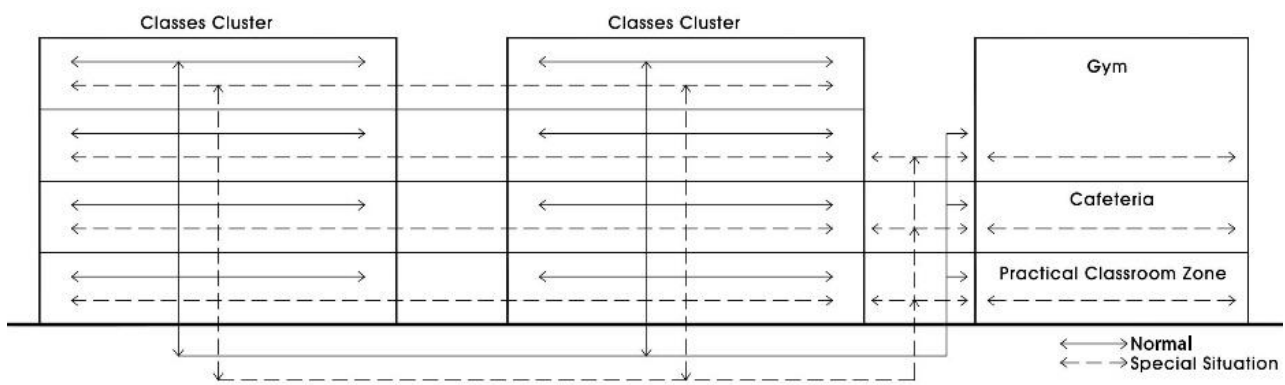

[Fig. 9] Concept of Zoning and Student Passage Guide

In the independent public facility assigned per cluster, sanitary arrangements and space composition are further expanded and emphasized than the current standards so that students' hygiene and health are prioritized even in normal times. In the context of COVID-19, it is essential to have the teaching aid storage to put away teaching materials from classrooms or workspaces. It is up to an architect whether to freely arrange creative convergence composite spaces for students such as exchange, rest, reading, class preparation, and faculty space in the cluster.

One of the plans in the flat configuration concept is to expand the width of a classroom toward the workspace and allow students to have face-to-face classes and mirrored classes while maintaining a 2meter distance. Another plan is that only a part of it is extended toward the workspace, and the back wall is moved, so that two classrooms can be expanded into one classroom, forming a space where a whole class of students can take class simultaneously[8].

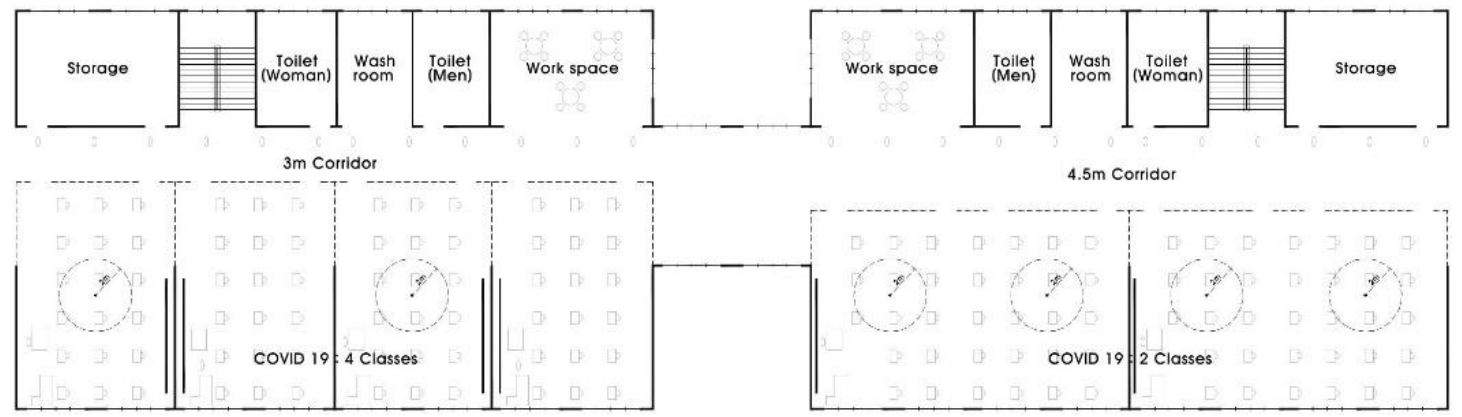

[Fig. 10] Concept of Flexible and variable zoning and plan changing as COVID-19

\subsection{Disscusion}

As stated in the introduction, a 26\% drop in the school-age population leads to the assumption that a quarter of current schools will disappear or a quarter of the space within the schools will no longer be 
utilized. Accordingly, since 2018 the South Korean government has implemented the principle of utilizing classrooms that are not used in schools and established the 'Measures to Improve the Utilization and Management of School Facilities'(Ministry of Education, Feb. 1, 2018), which ensures that empty classrooms in schools are first used for the original purposes of the school, such as the school curriculum and the establishment of adjoining kindergartens, and any residual facilities are used to meet regional needs and user requirements.

In fact, various factors of the future educational environment that can affect school space, such as a decrease in the number of students, a sudden change in the climate environment, and changes in Information and Communication Technology(ICT) learning environment, were fully predictable, and preparations have been underway. However, sudden pandemic variables such as COVID-19 were completely unforeseen and were not prepared for, but preparations are now in urgent demand. Such preparation requires major changes in education policies and overall education finance. Specifically, it entails changes in the curriculum, changes in teaching and learning methods, a reduction of the number of students per class, changes in teacher acquisition policies, changes in school architecture and space, and increases in the education budget.

The grand project of "space innovation" is in full swing at school sites in South Korea. Everyone would readily agree to its background and purpose. However, one may question whether the means of the innovation have been desirable. The characteristics of the government-led implementation method with features distinct to South Korea clearly demonstrate both the advantages and disadvantages of a project, as this approach consists in setting a goal, period, and project cost, and producing results consistent with the goal by a preset deadline. Consequently, it is clearly observed both positive and negative results. The architects participating in this project did not study the curriculum and educational policy or have any experience in school affairs. Therefore, there have been criticism of a failure to have a proper dialog with the principal and teachers, whose opinions are frequently ignored. The collection of students' feedback to promote user participation oddly converges on the same conclusion as if there is a correct answer that someone has already made up. Due to burden of the critical gaze on architects who say they've done their job, many of them end up avoiding the project either voluntarily or intentionally in future. Even if this current strong trend dissipates, people welcome the fact that schools are becoming one of the most important fields in our architecture. However, everyone will understand that this method is not sustainable if it is merely to improve old facilities instead of carrying out fundamental reforms that incorporate changes in the curriculum or system. There may be people who believe that transforming a school into a colorful interior and a playground is genuine space innovation, but people should not commit a failure to capture the background and purpose of this project.

This may be a very important reason to emphasize that this study was conducted.

Once a school is built, it can last five decades or even a hundred years or more. School and space once built could be used as they are thirty or fifty years from now. The fixed architecture and space themselves should not become constraints that make it difficult to respond to new curricula, users, environment, and other changes. It is clear that they must fit into the present age when schools are being built, but they must be able to respond flexibly to various and unpredictable changes at any point in the future. A school space with such flexibility and variability is the essence of school space innovation that is the focus of current discussions, as it aims to create a space that can stimulate imagination without restricting users' activities. The flat configuration presented earlier is a concept that can simultaneously cope with expansion and flexibility in normal times and in COVID-19 situation.

\section{Conclusion}

The purpose of this study is to provide basic data that can be applied to the school site in the future by considering the decrease in the number of students, and school architecture and space plans to cope 
with the changes brought by the COVID-19 pandemic.

The conclusion of the study is as follows.

By examining alternatives for using school space that can respond to sudden pandemic variables such as COVID-19, it is deemed possible to respond by fully utilizing the school space with a plan that combines face-to-face class and class mirroring or a plan that combines face-to-face class and home mirroring. Some of the flexible responses for new schools or school spaces that can be expanded or remodeled are to convert the corridors into a multifunctional $7.5 \mathrm{~m}$ space, which combines the function of a $4.5 \mathrm{~m}$ wide workspace with the function of an ordinary $3 \mathrm{~m}$ passage, and to implement changes by means of zoning by grade level and improving student mobility guides designed to minimize student mobility and contact. The flat configuration presented earlier is a concept that can simultaneously cope with expansion and flexibility in normal times and in COVID-19 situation. These preparations and responses can be difficult in practice and require a lot of time, effort, and national financing. However, it is maybe believed that the result of those changes will also enable a dramatic improvement in the quality of school architecture and spatial environment in the future.

Until now, it is true that studies related to school spaces corresponding to pandemics such as COVID19 have not been conducted from various perspectives and methods, and since this study was also a basic study conducted in this reality, the conceptualization of the study is insufficient and case studies may not be universally justified. So, this is also a practical limitation of this study and in the fields of school architecture and spatial research.

Therefore, in the future, there is a need to conduct professional research to secure more objectivity and universality in various perspectives and opinions that may be raised in these fields. For this, by completely deviating from the complacent attitude of designing the existing almost identical school space, architects need to change the thinking and practice that have formed school architecture and space so far and plan schools that maximize flexibility and variability from now on. In addition, researchers should actively and realistically conduct research in the future on guides, planning elements and methods, and suggestions for institutions and policies for spaces that can cope with such educational environment

\section{Acknowledgments}

This work was supported by the research grant of Cheongju University (2020.03.01. 2022.02.28.)

\section{References}

[1]https://kosis.kr/statisticsList/statisticsListIndex.do?menuId=M_01_01\&vwcd=MT_ZTITLE\&parmTabId=M_01_01\& outLink=Y\&entrType=\#content-group, Mar 2 (2021)

[2] https://if-blog.tistory.com/11041, Mar 11 (2021)

[3] https://www.gantan.co.jp/works, Jun 23 (2020)

[4] https://if-blog.tistory.com/11041, Mar 12 (2021)

[5] http://www.archiega.co.kr/product/item.php?ca_id=101020\&it_id=1522133952, Jun 17 (2021)

[6] J. J. Jung, The Mixed Use Characteristics of General Media Centers in Japanese School for Student's Autonomy and Creative Learning Activities, Asia-pacific Journal of Multimedia Services Convergent with Art, Humanities, and Sociology (2019), Vol.9, No.1, pp.513-522, DOI : 10.35873/ajmahs.2019.9.1.052

[7] I. H. Park, K.Y. Kim, J. J. Jung, Comparative Analysis and Characteristics of Granted Area Standard in New Elementary Schools by City and Provincial Office of Education, Journal of the regional association of architectural institute of 
A Study on School Architecture and Spatial Planning Measures in Response to Changes Caused by COVID-19 Pandemic

korea, (2020), Vol.22, No.3, pp.115-126.

[8] http://cfsa.re.kr/ebook/ebook_view.html?pdf=10ed0b1ca0189ef0152b199806a118f7.pdf, Aug 11 (2021) 